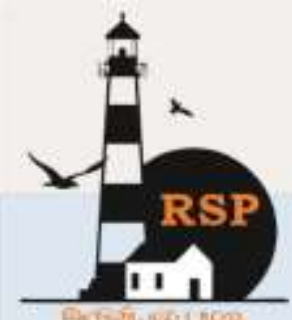

INTERNATIONAL RESEARCH JOURNAL ON ADVANCED SCIENCE HUB

\title{
Latest Developments in Logistics and Supply Chain Systems Implementations
}

Natesan Andiyappillai ${ }^{1}$, T.Prakash ${ }^{2}$

${ }^{1}$ Senior Business Analyst, NFI Industries, 1005 Laurel Oak Rd, Voorhees, NJ, 08043, USA.

${ }^{2}$ Professor, Department of Mechanical Engineering, SNS College of Technology (Autonomous), Coimbatore, India.

'natesan.andiyappillai@gmail.com, ${ }^{2}$ ttprakashmec@gmail.com

\begin{abstract}
As the technology evolves rapidly in the latest times, it is contributing to the developments of Logistics and Supply Chain Systems (LSCS) as well in the Logistics and Supply Chain business. Though there have been a number of researches done in the past decade or so on Logistics and Supply Chain Systems implementations, it appears that there is a huge gap between the number of latest researches on this area against the number of latest technological developments as the technological developments advances heavily. Hence, it is attempted in this research to understand the latest technological developments in a Logistics and Supply Chain Systems implementations in this research based on a case study conducted in a leading Logistics and Supply Chain organization. The pros and cons that the enterprises have at the recent times have been discussed in detail in this paper. As the technological changes are happening tremendously the way the enterprises are operating their entities, this study can be extended periodically to understand the benefits and challenges in the Logistics and Supply Chain Systems implementations at any given time.
\end{abstract}

Keywords: Logistics and Supply Chain Systems Implementations, LSCS.

\section{Introduction}

Supply Chain Management is a process of managing the supplying partners of an enterprise or enterprise entity. This process ensures the smooth flow of materials from supplier to customer and provides the visibility of material movement more closely on the entire supply channel. In order to manage the entire supply chain, organizations have been using Enterprise Resource Planning (ERP) applications as part of their IT strategy and model. A typical supply chain model is shown Fig.1. to depict how the materials flow from one end to another through different enterprise partners involved with; And, Logistics is an important process of storing and/or transporting the materials from one enterprise partner to another per enterprise requirements. Managing the Logistics and Supply Chain processes become complex for enterprise with no sophisticated IT systems, especially when the enterprise requirements are complex. The combination of low enterprise complexity and low enterprise volume may not require the advanced Logistics and Supply Chain Systems but it is much needed to manage the enterprise when it has the complex requirements and the high volume profile. A sample logistics diagram is shown fig.2. to depict how these inter-units are integrated into Logistics;

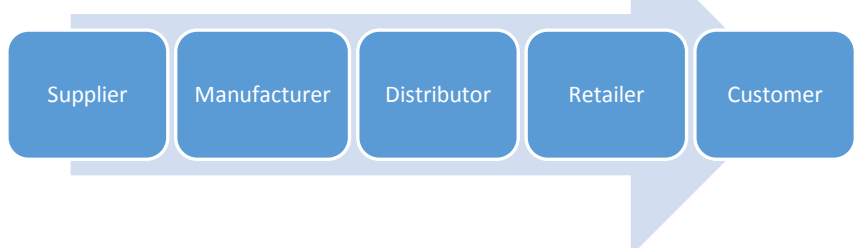

Fig 1. A Supply Chain channel 


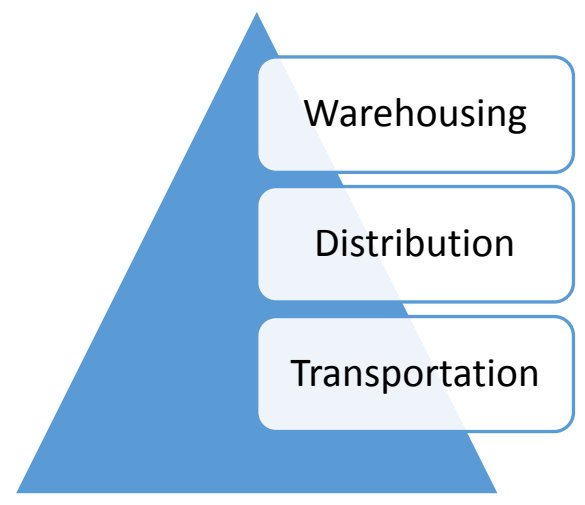

Fig 2. A Logistics flow diagram

Logistics enterprise use the Logistics and Supply Chain Systems to facilitate the Logistics and Supply Chain operations through IT systems for better tracking and managing the inventory effectively.

\section{Literature Survey}

Managing the material movement from one entity to another in an enterprise at right time, right inventory and at the right place is critical for the success of Logistics and Supply Chain enterprise. And, there are many entities involved in a supply chain process such as; Marketing, Sales, Sourcing, Manufacturing, Materials Storage, Distribution and Transportation etc. The more channels that are on a supply chain the more enterprise parameters involved in the enterprise. The more variables to the enterprise require the more sophisticated IT systems to manage and control the supply chain. Hence, the enterprise are implementing the Enterprise Resource Planning (ERP) systems in providing the better and clear supply chain visibility to their business partners. Logistics is a vital program in a supply chain when it comes to deliver the right product right time and to the right place. And, some of the primary services include in the Logistics enterprise are; Receiving, Putaway, Picking, Packing, Shipping, Replenishment, Materials movement, Customer Compliance and Value Added Services. It becomes impossible in managing all these processes without any IT systems when the enterprise model is complex and every changing due to the market behavior. And, one of the IT systems which help facilitate these Logistics processes smoothly is the Logistics and Supply Chain Systems.

There are researches in the Logistics and Supply Chain Systems which reveals the benefits attained by the enterprise. Logistics and Supply Chain Systems (LSCS) helps the Logistics enterprise in managing and tracking the Inventory [5,8]. A Logistics and Supply Chain System or LSCS primarily aims to control the movement and storage of materials within a Logistics and Supply Chain and process the associated transactions, including shipping, receiving, put-away and picking. A Logistics and Supply Chain System (LSCS) is a database driven computer application, to improve the efficiency of the Logistics and Supply Chain by directing cutaways and to maintain accurate inventory by recording Logistics and Supply Chain transactions. The systems also direct and optimize stock based on real-time information about the status of bin utilization [1-4].

Logistics and Supply Chain Systems helps the enterprise to maximize their operational efficiency in different areas in the processes. To meet these high performance goals, a way needs to be found to eliminate any waste from the Logistics and Supply Chain, to streamline its operations, and improve efficiency in every aspect of Materials storage activities. One of the most proactive ways of doing so is the use of a Logistics and Supply Chain System (LSCS) that is designed to speed up order turnaround time, improve inventory accuracy, provide instant order status information, manage Logistics and Supply Chain space and enhance labor productivity $[2,8]$.

The LSCS application is built based on different factors such as business specific requirements, General Logistics Requirements etc. Any LSCS application regardless of the enterprise complexity should be able to support some basic logistics functions. The LSCS must have tools and functions to support the main steps and logistic processes of inbound, production and outbound, such as: prereceiving of materials, concierge management, receiving, inbound quality control, storage, transfer, picking, cyclic counting and shipping [4,5].

Enterprise have been taking advantage of using LSCS and are getting benefited in many different ways and also to be able to meet the Metrics and SLAs. LSCS provides optimization, monitoring and control of complex Logistics and Supply Chain and distribution activities such as yard management, dock scheduling, order management, inventory management, and others in an efficient manner $[3,6]$.

Based on the research works published in the journals, conferences and on the other modes, it is 


\section{www.rspsciencehub.com}

clearly seen that only limited researches have been done in the past on LSCS Implementations and those researches have revealed both the benefits and constraints of using the system. And, there are very few attempts in the latest times on researching and investigating the latest trends in LSCS implementations to understand the latest happenings or issues or challenges. Hence, it is attempted in this research article by conducting a case study to analyze the issues/challenges on these LSCS implementations and finding the best possible solutions for those corresponding issues/challenges.

\section{Logistics and Supply Chain Systems Implementations}

The logistics enterprise implement the Logistics and Supply Chain Systems for process efficiency, improvement and transparency. And, a LSCS implementation would normally require the four important phases for a successful implementation per diagram shown in fig 3 . to be able to ensure the enterprise requirements are completely met by the IT solutions;

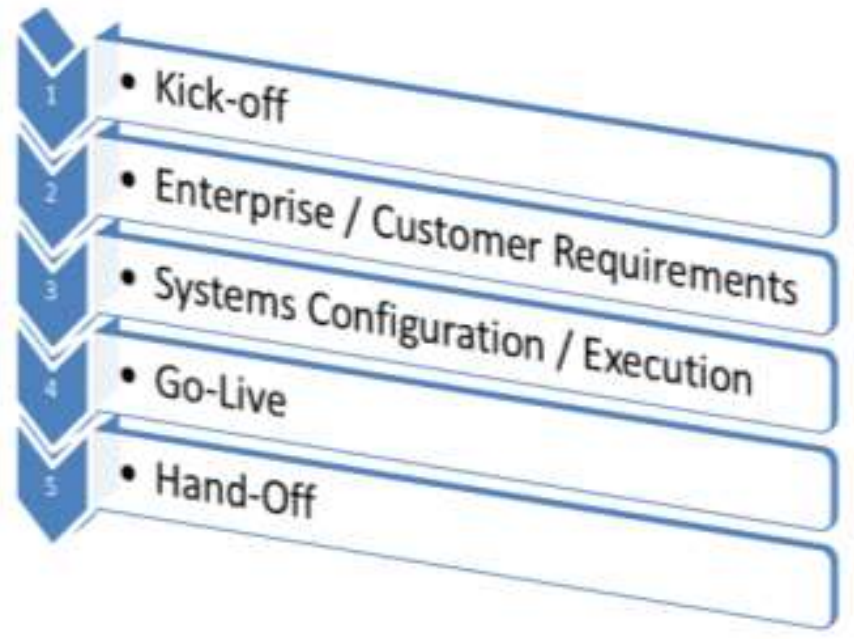

Fig 3. The phases of an LSCS Implementation life cycle

A LSCS implementation requires a variety of enterprise partners to be engaged and contributed at all times for a successful project delivery. There are challenges and issues in every LSCS implementation project based on the resources and data available for the successful delivery of the project.

\section{Research Methodology}

The methodology that has been used in this research is shown in Figure 4 and a variety of data and a lot of necessary data have been collected through different sources within the organization and analyzed and the findings are published appropriately. In simple terms to say, this case is analyzed in a qualitative approach.

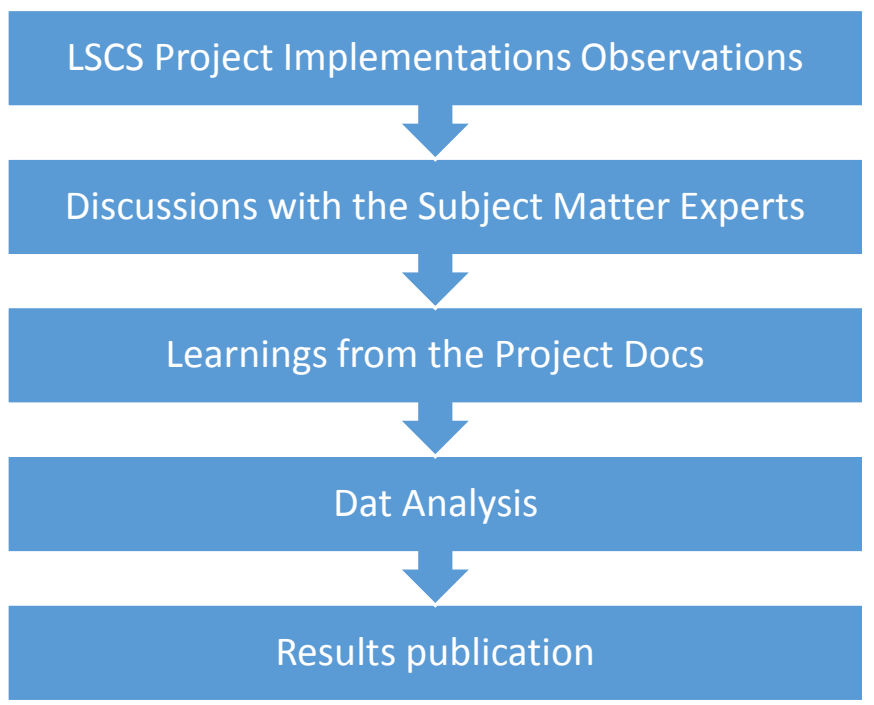

Fig 4. The Research Process

\section{A Case Study Analysis}

Every enterprise model is unique in the Logistics business hence every LSCS implementation too. In order to understand and analyze the latest trends in LSCS implementations, a case study has been conducted in a leading Logistics and Supply Chain company. And, this case study is performed based on the observations in LSCS implementations, discussions with the different resources and through project documentations. This company implements the LSCS application across their facilities in an effort to bring the unified IT LSCS solutions across the organization. This strategy also helps the organization to save the resources by eliminating the other legacy LSCS applications that have been used in the past decades. This company has a wellstructured IT organization which comprises of different internal entities per below to get participated and contributed to a LSCS implementation. And, the roles and responsibilities of each team are well defined and managed appropriately. Every entity in the project is an important business partner and committed to deliver the better possible LSCS solutions shown in fig.5 


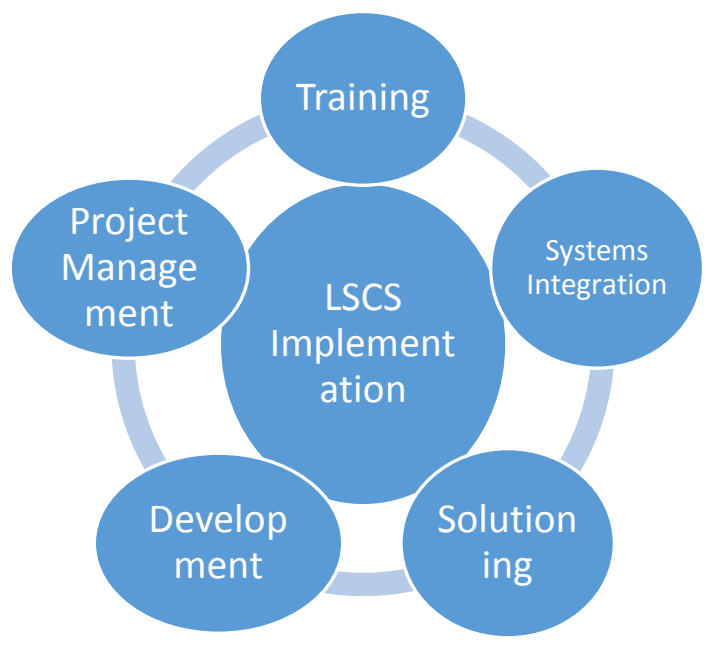

Fig 5. The Entities in a LSCS Implementation

The primary roles of each entity in a LSCS implementation project are listed below;

$>$ Project Management - To manage the project from start to end and ensure the smooth and successful LSCS implementation.

$>$ IT Solutions - To understand the enterprise requirements from customer, configuring the LSCS application per requirements, installing/managing the application and database.

$>$ EDI Integration - To integrate the Customer systems and any other external systems with LSCS systems and develop the EDI interfaces as per requirements.

$>$ Development - To develop any functionality that is needed for the enterprise and provides the corresponding solution through LSCS platform.

$>$ Training - To train the resources to be able to execute the LSCS functions in the application.

Based on this research, the vital factors that are influencing the LSCS implementations are categorized into four groups and each of them is detailed out below with the actions/pro-active measures that are being taken to accomplish a very successful LSCS implementation.

\subsection{Systems Integration}

Integrating the LSCS to the external systems such as Host and other IT Logistics systems is always a challenging and very important task in any
LSCS Implementation project as the data flow across all the systems should be smooth and efficient with no interruption. And, the following processes help to mitigate the challenges reside in the systems integration;

$>$ TMS Integration - Transportation Management System (TMS) is integrated with Logistics and Supply Chain System and this helps to do the better rate shopping with different parcel carriers and route the shipping accordingly based on the order data. This also helps to route the Shipments in the best network possible through network optimization.

$>$ Automated EDI Alerts - the EDI failure or delay at any point in the entire communication platform would be reported automatically to be able to resolve any such issue pro-actively and quickly. This also would help alert the enterprise or operations to prioritize a specific customer or order.

\subsection{LSCS Product Capacity and Capability}

Determining the hardware / software capacity and capability at the early phases of the project is another important challenge in the LSCS implementation project as this plays a vital role in ensuring the hardware and software compatibility for the enterprise and the usage of those resources to its maximum extent. The below decisions and determinations alleviate the challenges with respect to these factors;

$>$ Database architecture - determining the storage capacity and speed of the database and the number of machines based on the complexity and volume of the customer. And, also to look at the other tools such as Data Analytics, Reporting and Dashboards etc.

$>$ Standardization - Running the enterprise with the standard IT system solutions is easy as it has impact to the systems configuration, customer compliance, reporting etc. Hence, implementing the standard IT solutions is always recommendable for better, faster and cheaper implementations and also to manage the project with ease in the long run. Automation - there are two types of automations can be thoroughly looked into; i) setting up the multiple virtual instances for the application install 


\section{www.rspsciencehub.com}

is a vital for load balancing and running the systems with little to no impact for the enterprise. And, making the code deployments automated to all these virtual instances would help to avoid any errors. ii) Automating the Logistics and Supply Chain processes through MHE setup and configuration would help increase the operational efficiency.

\subsection{Enterprise Partners}

Aligning all the enterprise partners / business partners involved in the enterprise is one of the biggest challenges in any IT systems implementation and LSCS is no exception to that. And, any misalignment (includes the enterprise requirements) with any of the business partners would derail the project if not fixed as soon as it was identified. Below are the solutions to mitigate these risks;Vital Partners - Identifying and working closely with the vital enterprise partners / business partners are inevitable for the success of the project. And, the vital partners / business partners include the representatives from the customer, operations and IT and making the collective decisions would ensure the smooth and a very successful implementation in the entire project life cycle. Some of other business partners involved in the project are; the product vendor, training \& support and any other external partners involved. Requirements - understanding the requirements from the customer / enterprise in detail and documenting those requirements into an acceptable LSCS solution is mandatory for running the project in Green. These could be done in having customer / operations provide the Enterprise Requirements Document / Operational Requirement Document and conducting the Design sessions with business partners and then providing the Solution Design Document with the expected IT solutions.

\subsection{Visibility}

Providing the visibility on the project timeline and all the tasks involved in a project is crucial not just for monitoring the progress of the project but also be prepared for the consecutive activities proactively. The below tools help in providing the project visibility;

Project Timeline - This details out the tasks involved in a LSCS project and the corresponding timeline on each activity. This should be approved by the customer and any change to this by any
Volume 02 Issue 03 March 2020

partner would impact all the partners on the timeline of the deployment of the project or deployment cost or both.

\section{Conclusion}

It is so clear that Logistics and Supply Chain enterprise want to implement the Logistics and Supply Chain Systems to maximize their potential and gain competitive advantage in the market by providing the smooth Logistics services to their customers. At the same time, the implementation of LSCS should be aligned with the latest technological developments to be able support the latest technologies in the market. Based on this research conducted, the vital factors that are influencing the Logistics and Supply Chain Systems implementations are discussed and also the actions/pro-active measures taken by the enterprise to ensure a very successful LSCS implementation are detailed out. This research also reveals that the company is updating their LSCS implementation strategy based on the corresponding technological changes to be competitive in the market.

It is clearly seen that the company is making use of the technological developments and getting benefited from it and at the same time there are somes challenges hindering the organization from implementing them. Finally, as the technology evolves and impacts the current enterprise behavior, the similar research can be extended to understand the latest trends in LSCS implementation projects at any given time.

\section{References}

[1]Ramaa.A, K.N.Subramanya and T.N.Rangaswamy (2012), Impact of Logistics and Supply Chain System in a Supply Chain, International Journal of Computer Applications, Vol. 54 (1), Pages: $14-20$.

[2] H.Min (2006), The applications of Logistics and Supply Chain Systems: an exploratory study, International journal of Logistics Research and Applications, Vol. 6 (2), Pages: 111 - 126.

[3] Market Research Future (2017), Logistics and Supply Chain System Market: CAGR of $14 \%$ from 2017 to 2023 | Industry Trends, Enterprise Revenue Forecast and Statistics, Growth Prospective.

[4] Smith, J. D. (1998). The Logistics and Supply Chain management handbook. Tompkins press. 
[5] Nemati, H. R., Steiger, D. M., Iyer, L. S., \& Herschel, R. T. (2002). Knowledge Logistics and Supply Chain: an architectural integration of knowledge management, decision support, artificial intelligence and data warehousing. Decision Support Systems, 33(2), 143-161.

[6] Quaddus, M., \& Intrapairot, A. (2001). Management policies and the diffusion of data Logistics and Supply Chain: a case study using system dynamics-based decision support system. Decision Support Systems, 31(2), 223-240.

[7] Helo, P., \& Szekely, B. (2005). Logistics information systems: an analysis of software solutions for supply chain co-ordination. Industrial Management \& Data Systems, 105(1), 5-18.

[8] Helo, P., Xiao, Y., \& Roger Jiao, J. (2006). A web-based logistics management system for agile supply demand network design. Journal of Manufacturing Technology Management, 17(8), 1058-1077. 